\#139 Perceção da necessidade de tratamento ortodôntico precoce por Médicos Pediatras

Maria Vaz*, Pedro Mariano Pereira, Luís Proença

Instituto Universitário Egas Moniz

Objetivos: Os Médicos Pediatras são o grupo médico que mais acompanha as crianças durante todo o seu desenvolvimento e crescimento até à adolescência. É assim importante que este grupo profissional tenha competência para diagnosticar precocemente um problema ortodôntico e saber qual o momento ideal para o encaminhar para o especialista da área. Os objetivos deste projeto de investigação são percecionar se os Médicos Especialistas em Pediatria conseguem identificar um problema ortodôntico, saber qual o momento ideal para nele intervir e quais os que são prioritários tratar.

Materiais e métodos: Foi aplicado um questionário a dois grupos, online, via Google Forms ${ }^{\circledR}$. No total obteve-se 61 respostas. No grupo de estudo, constituído por Médicos Especialistas em Pediatria, obtiveram-se 33 respostas. No grupo de controlo, constituído por Médicos Dentistas Especialistas em Ortodontia obtiveram-se 23 respostas. O questionário continha três tipos de perguntas em relação a oito casos de má oclusão na dentição mista. Com a primeira pergunta pretendia-se avaliar a capacidade de identificar um problema ortodôntico, a segunda avaliava qual a altura ideal para tratar esse mesmo problema e a terceira pedia para organizar as imagens de acordo com a prioridade de tratamento.

Resultados: Na primeira pergunta, verificaram-se diferenças significativas entre as respostas dos dois grupos, nas más oclusões de mordida cruzada posterior bilateral e de diastemas $(p<0,05)$. Em todas as outras, as respostas foram concordantes. Na segunda pergunta, encontraram-se diferenças significativas para as más oclusões de mordida cruzada posterior e Classe II divisão 2. Na terceira pergunta, verificaram-se diferenças significativas nas medianas das más oclusões de mordida cruzada posterior, de Classe II divisão 1, de diastemas e de mordida aberta anterior $(\mathrm{p}<0,05)$.

Conclusões: Da interação dos resultados obtidos é possível inferir que os Médicos Pediatras, na generalidade, estão capacitados para identificar um problema ortodôntico em idades precoces. No entanto, nem sempre são capazes de diferenciar quais os problemas ortodônticos com maior prioridade de tratamento e qual a altura ideal para se intervir ortodonticamente. http://doi.org/10.24873/j.rpemd.2018.11.372

\#140 A avaliação do tratamento ortodôntico em pacientes em crescimento - resultados finais

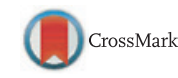

Berta Meireles, Ana Cristina Braga, Afonso Pinhão Ferreira*, Lucinda Gifford Faria, Marta Jorge, Maria João Ponces

Clínica Dentária Privada Portimão, Faculdade de Medicina Dentária da Universidade do Porto, Escola de Engenharia da Universidade do Minho, Centro ALGORITMI

Objetivos: Teoricamente, a apreciação dos resultados de um tratamento ortodôntico poderia ser efetuada através de uma avaliação quantitativa comparativa das medidas cefalo- métricas, iniciais e finais. Contudo, em pacientes em crescimento, estes estudos são questionáveis porque inviabilizam a identificação da localização anatómica das alterações. Assim, as sobreposições cefalométricas estruturais surgem como o método mais fidedigno no estudo das modificações em questão. Pretendeu-se perceber se, em pacientes em crescimento, a avaliação dos resultados do tratamento ortodôntico pela comunidade ortodôntica é realizada exclusivamente através das sobreposições cefalométricas.

Materiais e métodos: Na amostra inseriram-se os 162 case reports, do American Journal of Orthodontics and Dentofacial Orthopedics, publicados entre 2012 e 2016, inclusive, bem como no primeiro semestre de 2017 (volume 151). Os dados foram analisados através do programa IBM ${ }^{\circledR}$ SPSS $^{\circledR}$ Statistics, versão 24. No estudo analítico da relação entre as duas variáveis qualitativas usou-se o teste de independência do Qui-quadrado. Considerou-se como nível de significância estatística um $\mathrm{p}=0,05$.

Resultados: A avaliação dos resultados finais foi feita, conjuntamente, através das sobreposições cefalométricas e da comparação quantitativa de medidas cefalométricas em 59,3\% dos artigos consultados. Já em 34\% e 1,9\% da amostra, utilizou-se de uma forma isolada as sobreposições e a comparação quantitativa de medidas, respetivamente. Nos 8 casos restantes, não se procedeu nem à sobreposição de traçados nem à comparação quantitativa. Em 66,7\% dos casos em que se procedeu, apenas, a uma avaliação comparativa quantitativa de medidas cefalométricas, havia crescimento. Nos casos em que se realizou a sobreposição dos traçados cefalométricos e uma análise de medidas, 29,2\% referiam-se a pacientes em fase de crescimento. Verificou-se que não existia uma associação estatisticamente significativa entre o crescimento e o método de avaliação dos resultados do tratamento ortodôntico.

Conclusões: Os resultados permitem-nos concluir que, em pacientes em crescimento, a avaliação do tratamento ortodôntico não está a fazer-se exclusivamente através das sobreposições cefalométricas.

http://doi.org/10.24873/j.rpemd.2018.11.373

\section{\#141 A avaliação do tratamento ortodôntico e as sobreposições gerais - resultados finais}

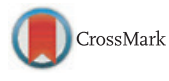

Berta Meireles, Ana Cristina Braga, Lucinda Gifford Faria, Jorge Dias Lopes, Afonso Pinhão Ferreira, Maria João Ponces*

Clínica Privada Portimão, Faculdade de Medicina Dentária da Universidade do Porto, Escola de Engenharia da Universidade do Minho, Centro ALGORITMI

Objetivos: Na avaliação dos resultados do tratamento ortodôntico, normalmente, as sobreposições a nível da base do crânio permitem obter uma visão de conjunto sem, contudo, objetivar se as alterações foram produzidas pelo crescimento ou pelo tratamento. Em fase de crescimento, somente as sobreposições estruturais são consideradas válidas, constituindo a sobreposição geral de Björk o gold standard. Em adultos, os outros procedimentos, nomeadamente os lineares, são aceites como igualmente válidos. Esta investigação teve como intuito identificar a sobreposição geral preferencialmente usada pelos 